\title{
Breeding Conditions Induce Rapid and Sequential Growth in Adult Avian Song Control Circuits: A Model of Seasonal Plasticity in the Brain
}

\author{
Anthony D. Tramontin, ${ }^{1}$ Vesta N. Hartman, ${ }^{3}$ and Eliot A. Brenowitz ${ }^{1,2,4}$ \\ Departments of ${ }^{1}$ Zoology, ${ }^{2}$ Psychology, ${ }^{3}$ The Graduate Program in Neurobiology and Behavior, and 4 The Virginia Merrill \\ Bloedel Hearing Research Center, University of Washington, Seattle, Washington 98195
}

In adult songbirds, seasonal changes in photoperiod and circulating testosterone $(T)$ stimulate structural changes within the neural song control circuitry. The mechanisms that control this natural plasticity are poorly understood. To determine how quickly and in what sequence the song nuclei respond to changing daylength and circulating $\mathrm{T}$, we captured 18 adult male white-crowned sparrows and kept them on short days for 12 weeks. We killed five of these birds and exposed the rest to long days (LD) and elevated T. We killed these birds either 7 or $20 \mathrm{~d}$ after LD $+\mathrm{T}$ exposure. We measured song nuclei volumes and cellular attributes, the mass of the vocal production organ (the syrinx), and song behavior. The neostriatal song control nucleus HVC (also known as "high vocal center"), added 50,000 neurons and increased in size within $7 \mathrm{~d}$ of exposure to LD $+\mathrm{T}$. Efferent targets of HVC, the robust nucleus of the archistriatum (RA), and area $\mathrm{X}$ of the parolfactory lobe grew more slowly and

During perinatal ontogeny, brain regions that compose neural circuits develop in a given sequence with a specific time course (e.g., Garey, 1984; Robinson and Dreher, 1990; Blakemore, 1991; Bottjer and Arnold, 1997). Many of these brain regions (or nuclei) continue to exhibit morphological plasticity in adult animals (Nottebohm, 1989; Wade and Crews, 1991; Hofman and Swaab, 1992; Chino, 1995; Woolley, 1998), but little is known regarding the sequence and the timing of plastic changes within and among these regions. A related question is whether the events that underlie adult plasticity match those observed during perinatal development (Kandel and O'Dell, 1992; Bailey and Kandel, 1993). Furthermore, there is scant information about behavioral changes that accompany adult brain changes. The avian song control system offers excellent opportunities to address these fundamental issues.

Song is a learned behavior that plays a critical role in reproduction (Catchpole and Slater, 1995). Song behavior, and the circuits that control it, are seasonally plastic in seasonally breeding species (Nottebohm, 1981; Nottebohm et al., 1986; Kroodsma

Received Aug. 9, 1999; revised Oct. 21, 1999; accepted Oct. 26, 1999.

This work was supported by the Virginia Merrill Bloedel Hearing Research Center and National Institutes of Health Grant MH53032 to E.A.B. A.D.T. is supported by the National Science Foundation. We thank Karin Lent for help with histology, Deborah Hutchinson for assistance with behavioral analyses, and Simone Meddle for providing birds. Anonymous reviewers provided helpful comments on this manuscript.

Correspondence should be addressed to Anthony D. Tramontin, The Rockefeller University, Box 210, 1230 York Avenue, New York, NY 10021. E-mail: tramona@ rockvax.rockefeller.edu

Copyright $\odot 2000$ Society for Neuroscience $0270-6474 / 00 / 200854-08 \$ 15.00 / 0$ were not significantly larger until day 20 of the study. The tracheosyringeal portion of the hypoglossal nucleus (nXIlts), which receives projections from RA and normally grows in response to seasonal cues, did not grow over the time course of this study. Syringeal mass increased within $7 \mathrm{~d}$ of LD $+T$ treatment. The anatomical changes in the brain were accompanied by behavioral changes in song production. On day 7 when the song circuitry was incompletely developed, male sparrows sang less stereotyped songs than males at day 20 with more completely developed song circuits. These results suggest that the song circuitry responds rapidly and sequentially to breeding-typical conditions (long days and elevated T), and that song stereotypy increases as nuclei within this circuitry grow.

Key words: plasticity; season; songbird; song system; testosterone; white-crowned sparrow and Miller, 1996; Smith et al., 1997a; Brenowitz et al., 1998). For example, white-crowned sparrows' (Zonotrichia leucophrys gambelii) songs are more stereotyped during the breeding season, and several of the song control nuclei can be up to $80 \%$ larger in breeding males than in nonbreeding males (Smith et al., 1995, 1997b; Soma et al., 1999). Several song nuclei contain gonadal steroid receptors (Arnold et al., 1976; Gahr, 1990; Balthazart et al., 1992; Brenowitz and Arnold, 1992; Smith et al., 1996; Soma et al., 1999) (Fig. 1), and the cyclical changes in the adult anatomy of these nuclei are mediated primarily by seasonal patterns of photoperiod and testosterone (T) secretion (Nottebohm, 1981; Rasika et al., 1994; Smith, 1996; Bernard et al., 1997; Smith et al., 1997a; Brenowitz et al., 1998; Soma et al., 1999; Tramontin and Brenowitz, 1999).

The song control system is a leading model of anatomical and functional plasticity in the adult brain. The nuclei within the song circuitry are easy to identify in histological sections, and their connectivity is well known (for review, see Brenowitz et al., 1997) (Fig. 1). The natural seasonal plasticity observed in wild songbird brains can be easily reproduced in captive animals by experimentally increasing day length and plasma sex steroid levels (Smith et al., 1995). Much has been learned by manipulating these factors and then analyzing brain structures several weeks or more later (Brenowitz et al., 1991; Bernard and Ball, 1995; Smith et al., 1995, 1997b; Bernard et al., 1997; Tramontin et al., 1998b). This approach, however, misses critical early events of dynamic song system growth. To understand the mechanisms that underlie adult brain plasticity, we must investigate changes as they occur rather than after they are completed. Another limitation of the tradi- 


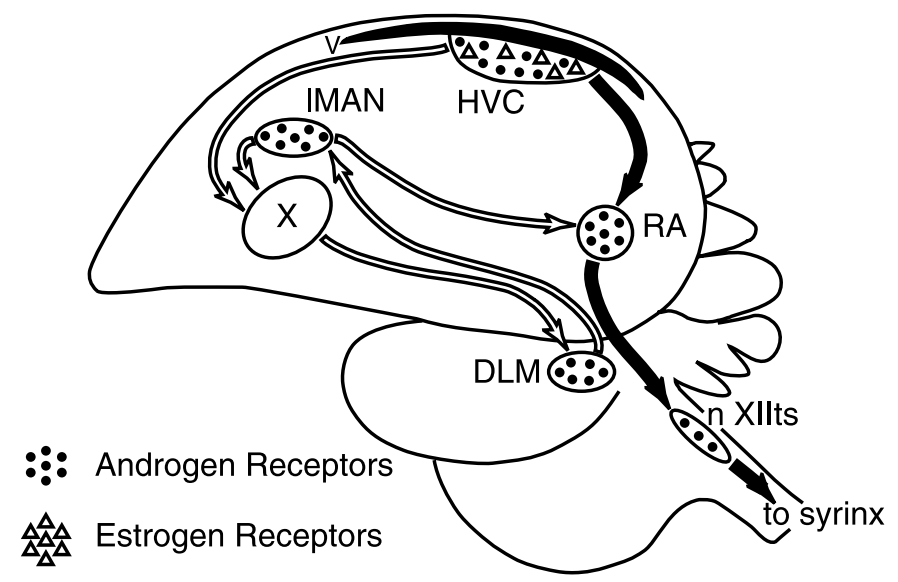

Figure 1. Simplified schematic sagittal view of the avian song control system illustrating the distribution of steroid receptors. Black arrows connect nuclei in the main descending motor circuit, and white arrows connect nuclei in the anterior forebrain circuit. DLM, Dorsolateral nucleus of the medial thalamus; $l M A N$, lateral portion of the magnocellular nucleus of the anterior neostriatum; $n X I I t s$, the tracheosyringeal portion of the hypoglossal nucleus; $R A$, the robust nucleus of the archistriatum; syrinx, vocal production organ; $V$, lateral ventricle; $X$, area $\mathrm{X}$ of the parolfactory lobe.

tional approach is that it focuses on individual song nuclei instead of considering the song control circuitry as an integrated whole. For example, we do not yet know the sequence of seasonal changes among the various nuclei of the song control circuitry or the degree to which changes in one nucleus may depend on changes in afferent or efferent targets. We have therefore taken a circuit analysis approach to examine the time course over which the song control system responds to long, spring-like days and increased circulating $\mathrm{T}$.

\section{MATERIALS AND METHODS}

Collection of animals and experimental treatments. We collected adult male Gambel's white-crowned sparrows in eastern Washington during their autumnal migration in September and October 1997. Eighteen males were housed indoors for 12 weeks on short days ( $\mathrm{SD}=8 \mathrm{hr}$ light) at $20^{\circ} \mathrm{C}$ to mimic the photoperiod and temperature on their wintering grounds and to ensure that all birds were sensitive to the stimulatory effects of breeding photoperiod and elevated T. White-crowned sparrows kept on SD indefinitely maintain regressed testes, basal or nondetectable levels of circulating $\mathrm{T}$, and regressed song control nuclei that are typical of the nonbreeding season (Middleton, 1965; Sansum and King, 1976; Smith et al., 1995, 1997c). Food and water were available ad libitum throughout the experiment.

On day 0 (D0) of the experiment, we killed five birds and placed the remaining 13 into two rooms (seven birds in one room and six in another). Previous experiments demonstrated that the song system was fully developed in this species within $40-45 \mathrm{~d}$ of exposure to long days and T (Smith et al., 1997b). On day 1 of the current experiment, 13 birds were photoshifted to long days ( $\mathrm{LD}=20 \mathrm{hr}$ light), typical of what they would experience on their Alaskan breeding grounds. On day 2, we implanted these 13 males subcutaneously with a SILASTIC capsule (1.47 $\mathrm{mm}$ inner diameter $\times 1.96 \mathrm{~mm}$ outer diameter) containing $12 \mathrm{~mm}$ of crystalline $\mathrm{T}$ to rapidly increase plasmas concentrations of this hormone into the range typical of wild breeding birds $(4-10 \mathrm{ng} / \mathrm{ml})$. After $\mathrm{T}$ implantation, we killed seven males on day 7 (D7) of the experiment and six males on day 20 (D20).

White-crowned sparrows exposed to spring environmental conditions in the field or to long days in the laboratory respond with growth of the song nuclei (Tramontin et al., 1998b; Soma et al., 1999). This growth is controlled primarily by the photo-induced increase in circulating $\mathrm{T}$ (Smith et al., 1997b). In both the field and the laboratory, circulating T increases slowly over several days, and the timing of this increase varies considerably between individual birds (Wingfield and Farner, 1978;
Tramontin et al., 1998b). The minimum concentration of circulating $\mathrm{T}$ that is required to induce song system growth is not yet known. These different sources of variability make it difficult to conduct a study of the time course of song system growth in response to gradually changing seasonal cues. We therefore designed our study so that all birds were exposed simultaneously to a photoperiod and $\mathrm{T}$ level known to be adequate to induce growth of the song system in this species. Smith et al. $(1995,1997 b)$ showed that exposing white-crowned sparrows to long days and $\mathrm{T}$ induced song system growth in captive sparrows that was similar to that observed in wild sparrows (Soma et al., 1999). Exposing all birds to an overnight shift from 8 to $20 \mathrm{hr}$ of light and implanting them with T pellets to produce physiological plasma $\mathrm{T}$ levels provided us with a discrete starting point against which to measure the time course of plastic growth in the song system. The results of this study therefore demonstrate the rapidity with which the song circuits can respond to conditions that are sufficient to induce growth during the breeding season.

Hormone assay and measurement of reproductive characteristics. On the morning that each male was killed, we collected $300 \mu$ l of whole blood by alar venepuncture into heparinized capillary tubes. The blood was immediately centrifuged, and the plasma was removed and stored at $-20^{\circ} \mathrm{C}$ until assay. We measured plasma $\mathrm{T}$ in a single radioimmunoassay using the Coat-A-Count Total Testosterone radioimmunoassay kit (Diagnostic Products). The minimum detectable plasma $\mathrm{T}$ concentration was 0.09 $\mathrm{ng} / \mathrm{ml}$. Samples with undetectable levels of steroid were treated as having concentrations at this detection limit for statistical analysis.

We measured the length and width of the left testis and estimated testis volume using the formula for the volume of an ovoid sphere (Wingfield et al., 1996). We also measured the length of the cloacal protuberance, a male secondary sex characteristic involved in sperm delivery, and the mass of the syrinx, the vocal production organ. The cloacal protuberance and the syringeal muscles grow in response to increased circulating androgens (Wingfield and Farner, 1978; Luine et al., 1980).

Brain histology and morphometry. Birds were deeply anesthetized by methoxyflurane inhalation and perfused through the heart with heparinized saline followed by $10 \%$ neutral-buffered formalin (NBF). Brains were post-fixed in $\mathrm{NBF}$ for at least 2 weeks, embedded in gelatin, cryoprotected in a $20 \%$ sucrose-NBF solution, and sectioned in the coronal plane at $50 \mu \mathrm{m}$ on a freezing microtome. Every other section was mounted and stained with thionin. The Nissl-defined borders of song nuclei coincide with the borders as defined by other labels (Johnson and Bottjer, 1993a; Rasika et al., 1994; Bernard and Ball, 1995; Smith et al., 1997b; Soma et al., 1999; Tramontin and Brenowitz, 1999).

We projected a magnified $(46 \times)$ image of each mounted section that contained a song nucleus profile $(100 \mu \mathrm{m}$ sampling interval). We traced onto paper the Nissl-defined borders of three nuclei in the main descending motor pathway of the song control circuitry: HVC (also known as "high vocal center"), the robust nucleus of the archistriatum (RA), and the tracheosyringeal portion of the hypoglossal nucleus (nXIIts) (Fig. 1). We also traced two nuclei in the anterior forebrain pathway of the song circuitry: area $\mathrm{X}$ of the parolfactory lobe, and the lateral portion of the magnocellular nucleus of the anterior neostriatum (IMAN). These tracings were scanned into a computer, and the cross-sectional area of each song nucleus profile was calculated using NIH Image software (version 1.57; Wayne Rasband, National Institutes of Health, Bethesda, MD). We estimated the volume of each nucleus using the formula for a cone frustum over each measured profile area (Smith et al., 1995). All brain measurements were made blind to the treatment group of each bird.

We expressed song nucleus volume in absolute terms (cubic millimeters) and as a percentage of the entire telencephalon. This second method of expression controlled for differences among groups in overall brain size and/or histological preparation. (Nucleus nXIIts is located in the brainstem and so was only expressed in absolute terms.) We estimated telencephalon volume by projecting onto paper a magnified $(14 \times)$ image of every sixth mounted section through the telencephalon $(600 \mu \mathrm{m}$ sampling interval). We traced the borders of either the left or right telencephalic hemisphere (alternated systematically after a random start), and scanned these tracings into a microcomputer. We defined the borders of the telencephalon as in DeVoogd et al. (1993), and Brenowitz et al. (1998). In sections where the telencephalon was contiguous with the diencephalon, we used the septomesencephalic tract, anterior commissure, and occipitomesencephalic tract as natural borders of the telencephalon. Telencephalon hemisphere volume was estimated with the formula for a cone frustum and multiplied by 2 to obtain total telencephalon volume; there was no volumetric difference between left and right 


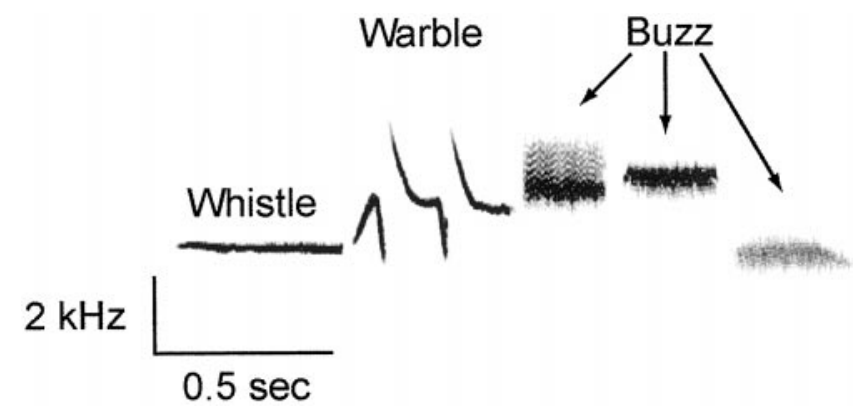

Figure 2. Sound spectrogram showing terminology used to describe Gambel's white-crowned sparrow song.

telencephalon volume. Telencephalon volume was then divided into song nucleus volume and multiplied by 100 to determine the percentage of the telencephalon that each song nucleus occupied.

Song system neuronal attributes. To measure differences in cellular neuronal attributes between groups, we used the random, systematic method described by Tramontin et al. (1998a). This method yields estimates of neuron density and number that do not differ from those obtained using the stereological optical disector method. We measured neuronal density, number, and somal area in HVC, RA, and nXIIts. Neurons were distinguished from glia by having one or two round nucleoli, a well-defined nuclear envelope, nongranular cytoplasm, and/or an obvious axonal hillock (Goldman and Nottebohm, 1983; Smith et al., 1995, 1997b; Tramontin et al., 1998a).

Song behavior. For 2-3 d before killing, we recorded song behavior from birds in each $\mathrm{LD}+\mathrm{T}$ treatment group to assess song variability (i.e., the inverse of stereotypy). Birds held on short days never sang and so were not included in any behavioral analyses. Five of the seven birds killed on day 7 sang while all of the birds killed on day 20 sang. We attached tie-clip microphones to each bird's cage to obtain high-quality recordings of each individual's songs. We confirmed the identity of each singing bird visually with a video camera placed within the room. Twenty consecutive songs from each singing male were analyzed to measure song stereotypy using customized software (J. Burt, University of Washington). We digitized each song and displayed it on the computer screen as a sound spectrogram. On this spectrogram, we used time and frequency cursors to measure four temporal and six spectral attributes of song (Fig. 2 , see Table 4). For each song attribute, we calculated the mean value for each individual bird (averaged from 20 consecutive recordings), and then averaged those means among birds within a treatment group. Thus, the data presented in Table 4 are group means $( \pm$ SEM) of individual means. We tested whether the absolute values of these song attributes differed between groups as indicated by group means. To determine if groups differed in the stereotypy of these attributes, we compared coefficients of variation $(\mathrm{CV}=\mathrm{SD} /$ mean $\times 100)$ between treatment groups. Song attributes were measured blind to treatment group.

On the morning of killing (immediately after lights on), we recorded 90 min of spontaneous singing to compare song rate between the two LD + $\mathrm{T}$ treatment groups. We used a Sony TCD5M cassette tape recorder and a Sennheiser ME 80 directional microphone to record all singing in the room. Each male in this experiment sang a different single song type, which allowed us to identify and distinguish the individual birds who sang during the recording period.

Statistics. All comparisons of song system anatomy, body measures, and plasma steroid levels were performed among groups using one-way ANOVA. Post hoc pairwise comparisons between groups were performed with Fisher's Protected Least Significant Difference tests (PLSD) (two-tailed). HVC, RA, and nXIIts neuronal attribute data (neuron size, density, and number) were log-transformed to meet parametric criteria for normality and equal variance among groups. Song behavior was compared between the D7 and D20 groups using one-tailed $t$ tests (D0 birds never sang). One-tailed tests were used because we were testing the hypothesis that song variability would decrease with time. This directional hypothesis was based on the results of Smith et al. (1995, 1997a), and Brenowitz et al. (1998), who demonstrated that song structure is more stereotyped in breeding- than nonbreeding-condition whitecrowned sparrows and song sparrows (Melospiza melodia morphna). For all tests, the $\alpha$ level was 0.05 .

\section{RESULTS \\ Plasma testosterone levels and reproductive characteristics}

Increased daylength and T implants significantly increased circulating $T$ in our implanted male birds (Table 1). Males killed either on day 7 or day 20 had significantly higher plasma T levels than males killed on day 0 . This circulating $\mathrm{T}$ was within the physiological range for breeding male sparrows $(4-10 \mathrm{ng} / \mathrm{ml})$ and induced significant growth in two peripheral androgen-sensitive tissues. The length of the cloacal protuberance and the mass of the syrinx both increased significantly within $7 \mathrm{~d}$ of the onset of treatment (Table 1).

As expected, all males in this study had fully regressed testes that did not grow during the course of the study (Table 1). White-crowned sparrows recrudesce their gonads each year in preparation for breeding, when mean gonadal volume becomes greater than $100 \mathrm{~mm}^{3}$ (Wingfield et al., 1996). This annual gonadal growth is under the control of hypothalamic gonadotropin-releasing hormone, which induces folliclestimulating hormone secretion from the anterior pituitary. Exogenous $\mathrm{T}$ administration inhibits the secretion of gonadotropins through endogenous negative feedback mechanisms (Matt, 1980).

\section{Song system morphometry}

The song control system showed significant growth in response to $\mathrm{LD}+\mathrm{T}$ treatment. The size of the telencephalon also differed slightly, but significantly among treatment groups (Table 2). To control for these group differences in overall telencephalon size, we divided song nucleus volume by telencephalon volume (see Materials and Methods). By expressing song nucleus volume as a percentage of the telencephalon, we confirmed that HVC, RA, and area $\mathrm{X}$ grew specifically in response to $\mathrm{LD}+\mathrm{T}$ (data and statistics in Table 2). The time course of growth, however, was not parallel among these three nuclei. HVC grew more rapidly than either of its two efferent targets, RA and area X (Table 2, Fig. 3). Note in Figure 3 that when expressed as the percentage of their maximum size, $\mathrm{HVC}$ was relatively smaller than RA and area X at day 0 , but was relatively larger than both of these nuclei at day 7. On day 7, HVC was $94 \%$ of its full breeding size, suggesting that most of the growth of HVC was accomplished by this time. On day 20, HVC was fully grown and was not different from HVC size in white-crowned sparrows similarly treated with LD + $\mathrm{T}$ for $44 \mathrm{~d}$ by Smith et al. (1997b) $(t=1.119 ; \mathrm{df}=11 ; p=0.29)$.

The efferent targets of HVC, RA, and area X, also grew in response to $\mathrm{LD}+\mathrm{T}$, but the growth of these regions was delayed with respect to HVC (Table 2, Fig. 3). Between days 0 and 7, RA did not grow significantly. Between days 7 and 20, however, RA did grow significantly and was fully developed by day 20 . On day 20 , RA size was the same as that reported for white-crowned sparrows similarly treated with $\mathrm{LD}+\mathrm{T}$ for $44 \mathrm{~d}$ by Smith et al. (1997b) $(t=0.151 ; \mathrm{df}=11 ; p=0.883)$. Area $\mathrm{X}$ also responded to $\mathrm{LD}+\mathrm{T}$ (Table 2, Fig. 3). Between days 0 and 7, area $\mathrm{X}$ did not grow significantly. By day 20, however, area $\mathrm{X}$ reached its full breeding size and was similar to area $X$ size in sparrows exposed to $\mathrm{LD}+\mathrm{T}$ for $44 \mathrm{~d}$ by Smith et al. (1997b) $(t=0.499 ; \mathrm{df}=11 ; p=$ $0.63)$.

Two song nuclei did not show significant growth over the time course of this study. The sizes of IMAN and nXIIts did not increase at any time in response to $\mathrm{LD}+\mathrm{T}$ treatment (Table 2). 
Table 1. Plasma testosterone levels and secondary sexual characteristics (mean \pm SEM)

\begin{tabular}{|c|c|c|c|c|c|}
\hline & $\begin{array}{l}\text { Day 0 } \\
(n=5)\end{array}$ & $\begin{array}{l}\text { Day } 7^{*} \\
(n=7)\end{array}$ & $\begin{array}{l}\text { Day } 20^{*} \\
(n=6)\end{array}$ & $\begin{array}{l}\text { ANOVA } \\
F\end{array}$ & $\begin{array}{l}\text { ANOVA } \\
p\end{array}$ \\
\hline Plasma testosterone $(\mathrm{ng} / \mathrm{ml})$ & $0.12 \pm 0.03^{a}$ & $11.67 \pm 0.86^{b}$ & $9.42 \pm 0.88^{b}$ & 57.134 & $<0.001$ \\
\hline Cloacal protuberance length $(\mathrm{mm})$ & $2.36 \pm 0.14^{a}$ & $4.76 \pm 0.14^{b}$ & $5.98 \pm 0.44^{c}$ & 39.301 & $<0.001$ \\
\hline Syrinx mass (mg) & $12.30 \pm 0.49^{a}$ & $16.20 \pm 0.64^{b}$ & $17.30 \pm 0.99^{b}$ & 10.835 & 0.001 \\
\hline Gonad volume $\left(\mathrm{mm}^{3}\right)$ & $0.51 \pm 0.12$ & $0.66 \pm 0.11$ & $0.62 \pm 0.12$ & 0.410 & 0.671 \\
\hline
\end{tabular}

*Interval between exposure to LD $+\mathrm{T}$ and killing.

${ }^{a, b, c}$ Within rows, values with different superscripts differ significantly from each other, Fisher's PLSD, $p<0.05$ (two-tailed).

Table 2. Brain morphometry (mean \pm SEM)

\begin{tabular}{|c|c|c|c|c|c|}
\hline & $\begin{array}{l}\text { Day 0 } \\
(n=5)\end{array}$ & $\begin{array}{l}\text { Day 7* } \\
(n=7)\end{array}$ & $\begin{array}{l}\text { Day 20* } \\
(n=6)\end{array}$ & $\begin{array}{l}\text { ANOVA } \\
F\end{array}$ & $\begin{array}{l}\text { ANOVA } \\
p\end{array}$ \\
\hline HVC volume $\left(\mathrm{mm}^{3}\right)$ & $0.554 \pm 0.039^{a}$ & $0.937 \pm 0.082^{b}$ & $1.012 \pm 0.121^{b}$ & 6.450 & 0.010 \\
\hline RA volume $\left(\mathrm{mm}^{3}\right)$ & $0.339 \pm 0.040^{a}$ & $0.405 \pm 0.037^{a, b}$ & $0.494 \pm 0.030^{b}$ & 4.357 & 0.032 \\
\hline Area $X$ volume $\left(\mathrm{mm}^{3}\right)$ & $1.441 \pm 0.166$ & $1.734 \pm 0.188$ & $2.159 \pm 0.204$ & 3.309 & 0.065 \\
\hline IMAN volume $\left(\mathrm{mm}^{3}\right)$ & $0.144 \pm 0.010$ & $0.144 \pm 0.007$ & $0.161 \pm 0.024$ & 0.398 & 0.678 \\
\hline nXIIts volume $\left(\mathrm{mm}^{3}\right)$ & $0.074 \pm 0.006$ & $0.071 \pm 0.006$ & $0.092 \pm 0.013$ & 1.621 & 0.230 \\
\hline Telencephalon volume $\left(\mathrm{mm}^{3}\right)$ & $596.20 \pm 16.35^{a}$ & $554.39 \pm 13.84^{b}$ & $542.50 \pm 9.61^{b}$ & 3.960 & 0.042 \\
\hline HVC/Telencephalon $(\%)$ & $0.092 \pm 0.008^{a}$ & $0.167 \pm 0.016^{b}$ & $0.183 \pm 0.019^{b}$ & 8.477 & 0.003 \\
\hline RA/Telencephalon $(\%)$ & $0.057 \pm 0.006^{a}$ & $0.073 \pm 0.006^{a}$ & $0.091 \pm 0.006^{b}$ & 7.546 & 0.005 \\
\hline Area X/Telencephalon (\%) & $0.243 \pm 0.031^{a}$ & $0.314 \pm 0.037^{a, b}$ & $0.398 \pm 0.038^{b}$ & 4.159 & 0.037 \\
\hline IMAN/Telencephalon (\%) & $0.024 \pm 0.002$ & $0.026 \pm 0.002$ & $0.030 \pm 0.005$ & 0.799 & 0.468 \\
\hline
\end{tabular}

*Interval between exposure to LD $+\mathrm{T}$ and killing.

${ }^{a, b, c}$ Within rows, values with different superscripts differ significantly from each other, Fisher's PLSD, $p<0.05$ (two-tailed).

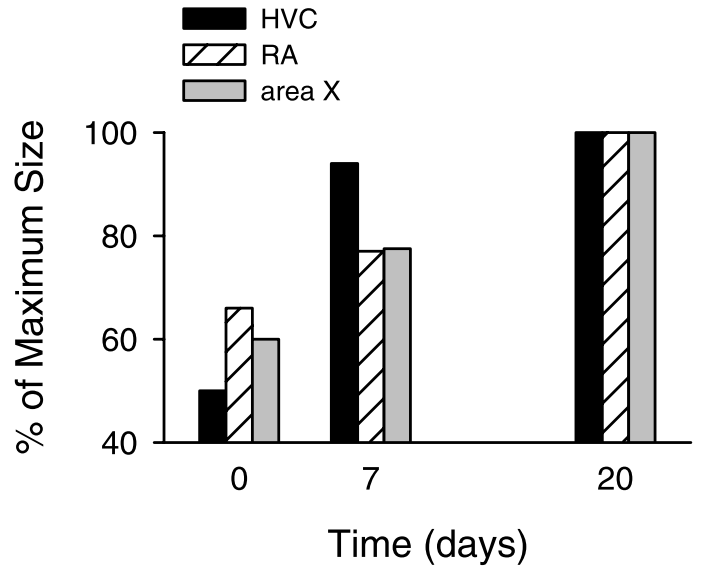

Figure 3. Song system growth in response to long days and testosterone treatment that simulates breeding season conditions. Song nuclei sizes for each bird were expressed as a percentage of each bird's telencephalon volume (Table 2). To determine how quickly each nucleus grew toward its maximum size, mean song nucleus size at each time point was divided by mean song nucleus size at day 20. Note that HVC (black bars), RA (hatched bars), and area X ( gray bars) were all fully developed at day 20 (see Results and Discussion).

\section{Song system neuronal attributes}

To investigate the time course of cellular changes in the song system, we measured neuron size, density, and number in HVC, $\mathrm{RA}$, and $\mathrm{nXIIts.} \mathrm{LD}+\mathrm{T}$ treatment rapidly increased two of these measures within HVC (Fig. 4). LD + T significantly increased the size of HVC neurons $\left(F_{(2,17)}=17.823 ; p<0.001\right)$. Within $7 \mathrm{~d}$ of LD + T treatment, HVC neurons were $26 \%$ larger than at day 0 (D0 vs D7, $p<0.001$ ). Neuron size did not increase further between days 7 and 20 (D7 vs D20, $p=0.55$ ). The density of
HVC neurons did not change in response to $\mathrm{LD}+\mathrm{T}\left(F_{(2,17)}=\right.$ $0.916 ; p=0.421)$. We have never observed a seasonal change in HVC neuron density in this species (Smith et al., 1995, 1997b; Tramontin et al., 1998a). HVC neuron number, however, was significantly affected by LD $+\mathrm{T}$ treatment $\left(F_{(2,17)}=5.007 ; p=\right.$ 0.022). Between days 0 and 7, mean HVC neuron number increased by nearly 50,000 neurons (67\%) (D0 vs D7, $p=0.01$ ). Neuron number did not increase further between days 7 and 20 (D7 vs D20, $p=0.90$ ).

$\mathrm{LD}+\mathrm{T}$ treatment also significantly affected two cellular attributes within RA (Fig. 4). The cross-sectional soma area of RA neurons increased significantly in response to $\mathrm{LD}+\mathrm{T}\left(F_{(2,17)}=\right.$ 9.552; $p=0.002$ ). Between days 0 and 7 , mean RA neuron size increased by $25 \%$ (D0 vs D7, $p=0.01$ ). This change in cell size occurred despite the fact that the size of RA did not change significantly until after $20 \mathrm{~d}$ of LD $+\mathrm{T}$ (Table 2, Fig. 3). Neuron size in RA only increased an additional $10 \%$ between days 7 and 20 (D7 vs D20, $p=0.21$ ). The density of RA neurons was also significantly affected by LD $+\mathrm{T}$ treatment $\left(F_{(2,17)}=3.959 ; p=\right.$ 0.04). RA neuron density decreased in response to $\mathrm{LD}+\mathrm{T}$, but this was not statistically significant until day 20 when neuron density was $24 \%$ lower than at day 0 (D0 vs D20, $p=0.02$ ). Thus, the time course of the decrease in neuron density was similar to the time course of the overall growth of this nucleus. Neuron number in RA was not significantly affected by LD $+\mathrm{T}$ treatment $\left(F_{(2,17)}=0.430 ; p=0.66\right)$. We have never observed a seasonal change in RA neuron number in this species (Smith et al., 1995, 1997b; Tramontin et al., 1998a).

$\mathrm{LD}+\mathrm{T}$ treatment increased the size of nXIIts motoneurons by $39 \%$, but this difference just failed to reach significance (Table 3 ). We observed no changes in nXIIts neuron density or number over the time course of this study (Table 3). 
Figure 4. Increased day length and testosterone administration induced significant neuronal attribute changes in $\mathrm{HVC}$ and RA (mean \pm SEM). Data for HVC are shown in the left three panels, and data for RA are shown in the right three panels. The cross-sectional areas of $\mathrm{HVC}$ and RA neuronal somata both increased significantly by day 7 . HVC neuron number was significantly increased by day 7 . RA neuron density was significantly decreased at day 20 . Letters above curves indicate statistical differences among groups.
HVC
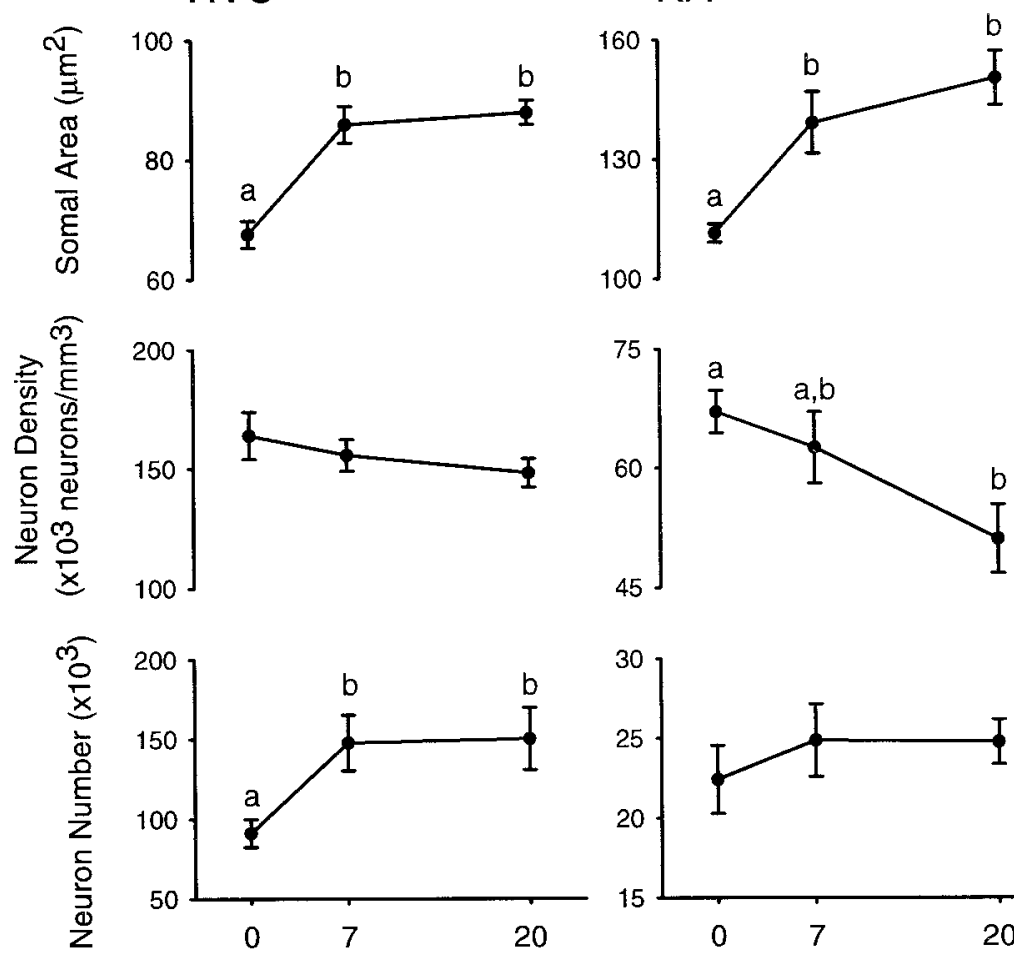

Time (days)
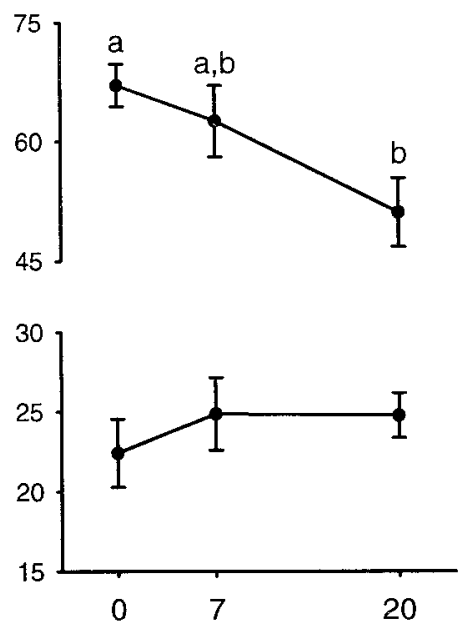

Table 3. Neuronal attributes of song nucleus nXIIts (mean \pm SEM)

\begin{tabular}{|c|c|c|c|c|c|}
\hline & $\begin{array}{l}\text { Day 0 } \\
(n=5)\end{array}$ & $\begin{array}{l}\text { Day } 7 * \\
(n=7)\end{array}$ & $\begin{array}{l}\text { Day } 20^{*} \\
(n=6)\end{array}$ & $\begin{array}{l}\text { ANOVA } \\
F\end{array}$ & $\begin{array}{l}\text { ANOVA } \\
p\end{array}$ \\
\hline Neuronal somal area $\left(\mu \mathrm{m}^{2}\right)$ & $272.46 \pm 20.25$ & $331.50 \pm 24.24$ & $350.96 \pm 16.19$ & 3.449 & 0.059 \\
\hline Neuron density $\left(\times 10^{3}\right.$ neurons $\left./ \mathrm{mm}^{3}\right)$ & $32.89 \pm 1.69$ & $33.97 \pm 1.82$ & $34.19 \pm 1.15$ & 0.164 & 0.850 \\
\hline Neuron number $\left(\times 10^{3}\right)$ & $2.44 \pm 0.24$ & $2.39 \pm 0.22$ & $3.12 \pm 0.43$ & 1.248 & 0.315 \\
\hline
\end{tabular}

*Interval between exposure to $\mathrm{LD}+\mathrm{T}$ and killing.

\section{Song behavior}

We measured song rate and song stereotypy in birds exposed to long days and $\mathrm{T}$ for either 7 or $20 \mathrm{~d}$ (short-day birds at day 0 never sang and so were not analyzed). Song rate did not differ between males treated with $\mathrm{T}$ for 7 or $20 \mathrm{~d}(t=0.319$; $\mathrm{df}=11 ; p=0.38)$. Birds at day 7 sang at a mean rate of $1.11 \pm 0.41$ songs $/ \mathrm{min}$, whereas birds at day 20 sang at a mean rate of $0.93 \pm 0.33$ songs/min.

The absolute values of the 10 song attributes that we measured were not significantly different between groups (Table 4). Song stereotypy, however, did differ between groups. Table 4 shows the mean coefficients of variability for four temporal and six spectral measures of song variability. For every measure, the coefficient of song variability was lower (i.e., singing was more stereotyped) at $20 \mathrm{~d}$ after $\mathrm{T}$ treatment. For seven of these measures, the difference between groups reached statistical significance (Table 4).

\section{DISCUSSION}

Previous studies in songbirds have clearly demonstrated that prolonged exposure to breeding-typical seasonal cues results in dramatic seasonal song system growth (Nottebohm, 1980; Smith et al., 1995, 1997a,b,c). These studies have been pivotal in identifying environmental and physiological factors that influence adult plasticity in the vertebrate brain. They have not, however, examined the dynamic growth of the song control system while it is occurring. This approach is necessary for an understanding of the cellular and molecular events that mediate the seasonal plasticity of the song control system in adult birds. Toward this end, we examined the time course over which the song control circuitry responds to long spring-like days and elevated circulating $\mathrm{T}$.

$\mathrm{HVC}$ grew rapidly in response to $\mathrm{LD}+\mathrm{T}$. This treatment increased mean HVC volume from $0.55 \pm 0.04$ (mean \pm SEM) to $0.94 \pm 0.22 \mathrm{~mm}^{3}$ within $7 \mathrm{~d}(69 \%$ growth). In a different study, Smith et al. (1997b) exposed castrated white-crowned sparrows to $\mathrm{LD}+\mathrm{T}$ for $44 \mathrm{~d}$ and reported a mean HVC volume of $1.18 \pm 0.09$ $\mathrm{mm}^{3}$, which corresponded to an increase of $80 \%$ compared to short-day birds. Smith et al. (1997b) used the same histological procedures as those used in the present study. Taken together, these results suggest that in the present study, HVC was almost entirely recrudesced by day 7 . This result is consistent with an anecdotal report of rapid seasonal HVC growth in American tree sparrows (Spizella arborea) (Ball, 1999). To our knowledge, such rapid structural changes of an entire adult brain region have not been reported in any other vertebrate system.

HVC and RA neurons grew significantly within $7 \mathrm{~d}$ of LD $+\mathrm{T}$ treatment. In RA, neuronal growth preceded the overall growth 


\begin{tabular}{|c|c|c|c|c|}
\hline & $\begin{array}{l}\text { Day } 7^{*} \\
(n=5)\end{array}$ & $\begin{array}{l}\text { Day 20* } \\
(n=6)\end{array}$ & $t^{* *}$ & $p^{* *}$ \\
\hline \multicolumn{5}{|c|}{ Whole song duration (sec) } \\
\hline Mean & $1.80 \pm 0.07$ & $1.84 \pm 0.09$ & -0.341 & 0.37 \\
\hline $\mathrm{CV}^{a}$ & $12.85 \pm 2.88$ & $6.35 \pm 2.09$ & 1.872 & 0.05 \\
\hline \multicolumn{5}{|c|}{ Whistle duration (sec) } \\
\hline Mean & $0.51 \pm 0.01$ & $0.52 \pm 0.02$ & -0.569 & 0.29 \\
\hline $\mathrm{CV}$ & $9.65 \pm 1.56$ & $5.45 \pm 1.24$ & 2.142 & 0.03 \\
\hline \multicolumn{5}{|c|}{ Warble duration (sec) } \\
\hline Mean & $0.41 \pm 0.03$ & $0.39 \pm 0.02$ & 0.479 & 0.32 \\
\hline $\mathrm{CV}$ & $5.42 \pm 1.26$ & $3.03 \pm 0.36$ & 1.987 & 0.04 \\
\hline \multicolumn{5}{|c|}{$1^{\text {st }}$ buzz duration $(\mathrm{sec})$} \\
\hline Mean & $0.24 \pm 0.01$ & $0.24 \pm 0.02$ & -0.252 & 0.41 \\
\hline $\mathrm{CV}$ & $9.35 \pm 2.32$ & $5.93 \pm 1.57$ & 1.566 & 0.08 \\
\hline \multicolumn{5}{|c|}{ Whistle minimum frequency $(\mathrm{kHz})$} \\
\hline Mean & $3.72 \pm 0.28$ & $3.70 \pm 0.25$ & 0.065 & 0.48 \\
\hline $\mathrm{CV}$ & $1.91 \pm 0.23$ & $1.02 \pm 0.17$ & 3.186 & 0.01 \\
\hline \multicolumn{5}{|c|}{ Whistle maximum frequency $(\mathrm{kHz})$} \\
\hline Mean & $4.18 \pm 0.30$ & $3.99 \pm 0.23$ & 0.505 & 0.32 \\
\hline $\mathrm{CV}$ & $2.59 \pm 0.43$ & $1.28 \pm 0.12$ & 3.166 & 0.01 \\
\hline \multicolumn{5}{|c|}{ Warble minimum frequency $(\mathrm{kHz})$} \\
\hline Mean & $2.95 \pm 0.17$ & $3.15 \pm 0.22$ & -0.706 & 0.25 \\
\hline $\mathrm{CV}$ & $3.24 \pm 0.35$ & $2.66 \pm 0.30$ & 1.248 & 0.12 \\
\hline \multicolumn{5}{|c|}{ Warble maximum frequency $(\mathrm{kHz})$} \\
\hline Mean & $5.12 \pm 0.29$ & $5.46 \pm 0.31$ & -0.789 & 0.23 \\
\hline $\mathrm{CV}$ & $3.68 \pm 0.33$ & $2.16 \pm 0.32$ & 3.308 & 0.01 \\
\hline \multicolumn{5}{|c|}{$1^{\text {st }}$ buzz minimum frequency $(\mathrm{kHz})$} \\
\hline Mean & $4.19 \pm 0.14$ & $4.23 \pm 0.11$ & -0.190 & 0.43 \\
\hline $\mathrm{CV}$ & $5.12 \pm 1.69$ & $2.27 \pm 0.27$ & 1.833 & 0.05 \\
\hline \multicolumn{5}{|c|}{$1^{\text {st }}$ buzz maximum frequency $(\mathrm{kHz})$} \\
\hline Mean & $6.08 \pm 0.17$ & $5.88 \pm 0.08$ & 1.142 & 0.14 \\
\hline $\mathrm{CV}$ & $3.60 \pm 0.83$ & $2.26 \pm 0.34$ & 1.598 & 0.08 \\
\hline
\end{tabular}

\footnotetext{
*Interval between exposure to LD + T and killing.

$* *$ Student's unpaired $t$ test (one-tailed). df $=9$ for all comparisons.

${ }^{a} \mathrm{CV}=\mathrm{SD} /$ mean $\times 100$.
}

of the entire nucleus. HVC developed too quickly for us to determine if neuronal growth preceded the overall growth in this brain region as well. A time course study with sampling between days 0 and 7 would provide this information. This is a critical question that might provide insight regarding the functional relevance of neuronal growth in HVC. Perhaps larger neurons are better able to provide trophic support to new neurons that are being incorporated into $\mathrm{HVC}$, or to neurons in area $\mathrm{X}$ and RA that may depend on trans-synaptic support from HVC neurons.

Neurons in nXIIts grew 39\% larger between days 0 and 20. This increase in neuron size just missed reaching statistical significance $(p=0.059)$, but may have done so given more time. Between days 0 and 20, the volume of nXIIts did not increase significantly. Smith et al. (1997b) reported that $44 \mathrm{~d}$ of LD $+\mathrm{T}$ treatment increased nXIIts volume by $50 \%$ in white-crowned sparrows. Taken together, these observations suggest that the growth of nXIIts neurons may precede the volumetric growth of the entire nucleus and that the seasonal development of nXIIts is delayed with respect to HVC and RA. Interestingly, we found that the mass of the syrinx, the efferent target of nXIIts, increased within $7 \mathrm{~d}$ of LD $+\mathrm{T}$. The syringeal muscles contain androgen receptors (Lieberburg and Nottebohm, 1979; Luine et al., 1980; Smith et al., 1996) and so may respond directly to changes in plasma T or its androgenic metabolites. nXIIts development may depend on anterograde trophic support from RA, retrograde support from the syrinx, or both.

The addition of $\sim 50,000$ neurons to HVC within $7 \mathrm{~d}$ of LD + $\mathrm{T}$ treatment is particularly interesting. Neuronal addition appears to be the primary means by which $\mathrm{HVC}$ volume increases before each annual breeding season. In a recent study investigating the regulation of neuronal survival in HVC, Rasika et al. (1999) injected female canaries (Serinus canaria) with the cell proliferation marker $\left[{ }^{3} \mathrm{H}\right]$ thymidine and then treated the birds with either empty SILASTIC implants or $\mathrm{T}$ implants. They reported that $10 \mathrm{~d}$ of $\mathrm{T}$ treatment increased the survival of ${ }^{3} \mathrm{H}$-labeled $\mathrm{HVC}$ neurons and that this treatment also increased overall HVC volume by $18 \%$. These results are consistent with the hypothesis that testosterone increases the volume of HVC by rescuing neurons that would otherwise die. Data from our study also support this hypothesis and further suggest that $7 \mathrm{~d}$ of $\mathrm{LD}+\mathrm{T}$ is nearly sufficient for the full development of HVC. Future studies with temporal sampling between days 0 and 7 will provide valuable insights into the regulation of neuronal proliferation and survival in the adult brain.

HVC sends axonal projections to two efferent targets in the song control system (Fig. 1). These two targets, RA and area X, 
responded more slowly than $\mathrm{HVC}$ to $\mathrm{LD}+\mathrm{T}$ treatment (Fig. 3). The delayed growth in RA and area $\mathrm{X}$ did not appear to be fully accomplished until day 20 when the sizes of both nuclei were similar to those reported by Smith et al. (1997b) in sparrows exposed to $\mathrm{LD}+\mathrm{T}$ for $44 \mathrm{~d}$. The delayed growth of RA and area $\mathrm{X}$ is consistent with two alternative hypotheses. These two nuclei may simply take longer to either initiate and/or complete growth in response to $\mathrm{LD}+\mathrm{T}$. Alternatively, the plastic growth of these two nuclei may depend on afferent input from HVC. This second hypothesis seems especially likely in the case of area $\mathrm{X}$, which does not express gonadal steroid receptors and presumably cannot respond directly to increased circulating $\mathrm{T}$ (Gahr and Metzdorf, 1997) (Fig. 1). Preliminary data from our laboratory suggest that afferent input from $\mathrm{HVC}$ is required for seasonal growth of RA as well as area X. In male white-crowned sparrows with unilateral HVC lesions, ipsilateral RA and area $\mathrm{X}$ did not grow in response to $\mathrm{LD}+\mathrm{T}$ treatment. Contralateral to the HVC lesion, however, the growth of RA and area X occurred normally (Brenowitz and Lent, 1999). Trans-synaptic factors from HVC might be sufficient to induce seasonal development of RA and area X (Akutagawa and Konishi, 1998; Rasika et al., 1999), or in the case of RA may facilitate the action of $\mathrm{T}$ within the nucleus itself.

Early ontogeny and adult plasticity of the song control circuits may exploit similar mechanisms. In young zebra finches (Poephila guttata; between 12 and $53 \mathrm{~d}$ after hatching), the volumetric growth of HVC appears to precede that of RA and area X (Bottjer et al., 1985). This developmental sequence within the juvenile song circuitry closely parallels the sequence of growth in the adult brain in response to conditions typical of the breeding season (i.e., LD + T). Also, lesions of HVC in juvenile zebra finches block the full development of RA and area X (Herrmann and Arnold, 1991; Johnson and Bottjer, 1993b; Akutagawa and Konishi, 1994). As stated above, unilateral lesions of HVC in adult Gambel's white-crowned sparrows prevent LD + T-induced growth of RA and area X ipsilateral to the lesion (Brenowitz and Lent, 1999). These observations suggest that it will be productive for future studies to explore the extent to which plasticity of adult neural circuits is regulated by cellular and molecular mechanisms similar to those that regulate plasticity during early development.

\section{Song behavior}

The functional relevance of the seasonal plasticity in the song system remains a critical but elusive problem. In wild, freely ranging white-crowned sparrows, the seasonal anatomical changes in the song control system and the seasonal growth of the syrinx are both correlated with seasonal changes in song stereotypy and song structure (Smith et al., 1995; Brenowitz et al., 1998; A. Tramontin, N. Perfito, J. Wingfield, and E. Brenowitz, unpublished data). During the breeding season when the song system and the syrinx are fully developed, the temporal and spectral structure of males' songs are highly stereotyped. During the nonbreeding season when the song system and the syrinx are fully regressed, males' songs are more variable in structure. In the present study, we were unable to measure song stereotypy in males maintained on short days because they did not sing. We were, however, able to measure song stereotypy in males at day 7 that had fully developed syringes, but only partially developed song control circuitry, and males at day 20 with large syringes and more completely developed song control systems. We found no differences in song production rate between the two groups, but males killed after $7 \mathrm{~d}$ of LD $+\mathrm{T}$ sang less stereotyped songs than males at day 20. These data indicate that there is not a simple relationship between song rate and the developmental state of the song circuitry. These data do suggest, however, that a large HVC and/or a large vocal production organ are not sufficient for stereotyped song production. It seems reasonable to hypothesize that a fully developed song control circuit is required to produce stereotyped songs, but not to sing at a high rate. A direct causal relationship between neural and behavioral changes, however, has yet to be established (for an extensive discussion of this issue, see Smith et al., 1997a).

\section{Conclusion}

There are other vertebrate models in which entire brain regions undergo extensive seasonal structural changes (Wade and Crews, 1991; Hofman and Swaab, 1992; Barnea and Nottebohm, 1994; Galea et al., 1999). It will be interesting to determine whether our observations of sequential growth in the adult song circuitry apply to these systems as well. It is known that plastic anatomical changes in the adult brain can occur rapidly (e.g., Woolley and McEwen, 1992). To what degree do these changes depend on afferent or efferent support? What factors are required for such putative trans-synaptic support? Is cellular growth a first step in changing the size of adult brain regions in other model systems? These questions should be addressed in a wide variety of neural circuits that show adult plasticity.

\section{REFERENCES}

Akutagawa E, Konishi M (1994) Two separate areas of the brain differentially guide the development of a song control nucleus in the zebra finch. Proc Natl Acad Sci USA 91:12413-12417.

Akutagawa E, Konishi M (1998) Transient expression and transport of brain-derived neurotrophic factor in the male zebra finch's song system during vocal development. Proc Natl Acad Sci USA 95:11429-11434.

Arnold AP, Nottebohm F, Pfaff DW (1976) Hormone concentrating cells in vocal control and other areas of the brain of the zebra finch (Poephila guttata). J Comp Neurol 165:487-511.

Bailey CH, Kandel ER (1993) Structural changes accompanying memory storage. Annu Rev Physiol 55:397-426.

Ball GF (1999) Neuroendocrine basis of seasonal changes in vocal behavior among songbirds. In: Neural mechanisms of communication (Hauser M, Konishi M, eds), Cambridge, MA: MIT.

Balthazart J, Foidart A, Wilson EM, Ball GF (1992) Immunocytochemical localization of androgen receptors in the male songbird and quail brain. J Comp Neurol 317:407-420.

Barnea A, Nottebohm F (1994) Seasonal recruitment of hippocampal neurons in adult free- ranging black-capped chickadees. Proc Natl Acad Sci USA 91:11217-11221.

Bernard DJ, Ball GF (1995) Two histological markers reveal a similar photoperiodic difference in the volume of the high vocal center in male European starlings. J Comp Neurol 360:726-734.

Bernard DJ, Wilson FE, Ball GF (1997) Testis-dependent and -independent effects of photoperiod on volumes of song control nuclei in American tree sparrows (Spizella arborea). Brain Res 760:163-169.

Blakemore C (1991) Sensitive and vulnerable periods in the development of the visual system. Ciba Found Symp 156:129-147.

Bottjer SW, Arnold AP (1997) Developmental plasticity in neural circuits for a learned behavior. Annu Rev Neurosci 20:459-481.

Bottjer SW, Glaessner SL, Arnold AP (1985) Ontogeny of brain nuclei controlling song learning and behavior in zebra finches. J Neurosci 5:1556-1562.

Brenowitz EA, Arnold AP (1992) Hormone accumulation in song regions of the canary brain. J Neurobiol 23:871-880.

Brenowitz EA, Lent K (1999) Seasonal growth of adult avian song nuclei requires afferent input. Soc Neurosci Abstr 25:864.

Brenowitz EA, Nalls B, Wingfield JC, Kroodsma DE (1991) Seasonal changes in avian song nuclei without seasonal changes in song repertoire. J Neurosci 11:1367-1374.

Brenowitz EA, Margoliash D, Nordeen KW (1997) An introduction to birdsong and the avian song system. J Neurobiol 33:495-500.

Brenowitz EA, Baptista LF, Lent K, Wingfield JC (1998) Seasonal 
plasticity of the song control system in wild Nuttall's white-crowned sparrows. J Neurobiol 34:69-82.

Catchpole CK, Slater PJB (1995) Bird song: biological themes and variations. Cambridge, MA: Cambridge UP.

Chino YM (1995) Adult plasticity in the visual system. Can J Physiol Pharmacol 73:1323-1338.

DeVoogd TJ, Krebs JR, Healy SD, Purvis A (1993) Relations between song repertoire size and the volume of brain nuclei related to song: comparative evolutionary analyses amongst oscine birds. Proc R Soc Lond B Biol Sci 254:75-82.

Gahr M (1990) Delineation of a brain nucleus: comparisons of cytochemical, hodological, and cytoarchitectural views of the song control nucleus HVc of the adult canary. J Comp Neurol 294:30-36.

Gahr M, Metzdorf R (1997) Distribution and dynamics in the expression of androgen and estrogen receptors in vocal control systems of songbirds. Brain Res Bull 44:509-517.

Galea LA, Perrot-Sinal TS, Kavaliers M, Ossenkopp KP (1999) Relations of hippocampal volume and dentate gyrus width to gonadal hormone levels in male and female meadow voles. Brain Res 821:383-391.

Garey LJ (1984) Structural development of the visual system of man. Hum Neurobiol 3:75-80.

Goldman SA, Nottebohm F (1983) Neuronal production, migration, and differentiation in a vocal control nucleus of the adult female canary brain. Proc Natl Acad Sci USA 80:2390-2394.

Herrmann K, Arnold AP (1991) Lesions of HVc block the developmental masculinizing effects of estradiol in the female zebra finch song system. J Neurobiol 22:29-39.

Hofman MA, Swaab DF (1992) Seasonal changes in the suprachiasmatic nucleus of man. Neurosci Lett 139:257-260.

Johnson F, Bottjer SW (1993a) Hormone-induced changes in identified cell populations of the higher vocal center in male canaries. J Neurobiol 24:400-418.

Johnson F, Bottjer SW (1993b) Induced cell death in a thalamic nucleus during a restricted period of zebra finch vocal development. J Neurosci 13:2452-2462.

Kandel ER, O'Dell TJ (1992) Are adult learning mechanisms also used for development? Science 258:243-245.

Kroodsma DE, Miller EH (1996) Ecology and evolution of acoustic communication in birds. Ithaca, NY: Cornell UP.

Lieberburg I, Nottebohm F (1979) High-affinity androgen binding proteins in syringeal tissues of songbirds. Gen Comp Endocrinol 37:286-293.

Luine V, Nottebohm F, Harding C, McEwen BS (1980) Androgen affects cholinergic enzymes in syringeal motor neurons and muscle. Brain Res 192:89-107.

Matt KS (1980) Sensitivity of the hypothalamic-pituitary axis to negative feedback in a photoperiodic species. In: Functional correlates of hormone receptors in reproduction (Mahesh VB, Muldoon TG, Saxena BB, Sadler WA, eds), pp 499-501. New York: Elsevier North Holland.

Middleton J (1965) Testicular responses of house sparrows and whitecrowned sparrows to short daily photoperiods with low intensities of light. Physiol Zool 38:255-266.

Nottebohm F (1980) Testosterone triggers growth of brain vocal control nuclei in adult female canaries. Brain Res 189:429-436.

Nottebohm F (1981) A brain for all seasons: cyclical anatomical changes in song control nuclei of the canary brain. Science 214:1368-1370.

Nottebohm F (1989) From bird song to neurogenesis. Sci Amer 260:74-79.

Nottebohm F, Nottebohm ME, Crane L (1986) Developmental and sea- sonal changes in canary song and their relation to changes in the anatomy of song-control nuclei. Behav Neural Biol 46:445-471.

Rasika S, Nottebohm F, Alvarez- Buylla A (1994) Testosterone increases the recruitment and/or survival of new high vocal center neurons in adult female canaries. Proc Natl Acad Sci USA 91:7854-7858.

Rasika S, Alvarez-Buylla A, Nottebohm F (1999) BDNF mediates the effects of testosterone on the survival of new neurons in an adult brain. Neuron 22:53-62.

Robinson SR, Dreher B (1990) The visual pathways of eutherian mammals and marsupials develop according to a common timetable. Brain Behav Evol 36:177-195.

Sansum EL, King JR (1976) Long-term effects of constant photoperiods on testicular cycles of white-crowned sparrows (Zonotrichia leucophrys gambelii). Physiol Zool 49:407-416.

Smith GT (1996) Seasonal plasticity in the song nuclei of wild rufoussided towhees. Brain Res 734:79-85.

Smith GT, Brenowitz EA, Wingfield JC, Baptista LF (1995) Seasonal changes in song nuclei and song behavior in Gambel's white-crowned sparrows. J Neurobiol 28:114-125.

Smith GT, Brenowitz EA, Prins GS (1996) Use of PG-21 immunocytochemistry to detect androgen receptors in the songbird brain. J Histochem and Cytochem 44:1075-1080.

Smith GT, Brenowitz EA, Beecher MD, Wingfield JC (1997a) Seasonal changes in testosterone, neural attributes of song control nuclei, and song structure in wild songbirds. J Neurosci 17:6001-6010.

Smith GT, Brenowitz EA, Wingfield JC (1997b) Roles of photoperiod and testosterone in seasonal plasticity of the avian song control system. J Neurobiol 32:426-442.

Smith GT, Brenowitz EA, Wingfield JC (1997c) Seasonal changes in the size of the avian song control nucleus HVC defined by multiple histological markers. J Comp Neurol 381:253-261.

Soma KK, Hartman VN, Wingfield JC, Brenowitz EA (1999) Seasonal changes in androgen receptor immunoreactivity in the song nucleus HVc of a wild bird. J Comp Neurol 409:224-236.

Tramontin AD, Brenowitz EA (1999) A field study of seasonal neuronal incorporation into the song control system of a songbird that lacks adult song learning. J Neurobiol 40:316-326.

Tramontin AD, Smith GT, Breuner CW, Brenowitz EA (1998a) Seasonal plasticity and sexual dimorphism in the avian song control system: stereological measurement of neuron density and number. J Comp Neurol 396:186-192.

Tramontin AD, Wingfield JC, Brenowitz EA (1998b) Contributions of social cues and photoperiod to seasonal plasticity in the adult avian song control system. J Neurosci 19:476-483.

Wade J, Crews D (1991) The relationship between reproductive state and "sexually" dimorphic brain areas in sexually reproducing and parthenogenetic whiptail lizards. J Comp Neurol 309:507-514.

Wingfield JC, Farner DS (1978) The annual cycle of plasma irLH and steroid hormones in feral populations of the white-crowned sparrow, Zonotrichia leucophrys gambelii. Biol Reprod 19:1046-1056.

Wingfield JC, Hahn TP, Wada M, Astheimer LB, Schoech S (1996) Interrelationship of day length and temperature on the control of gonadal development, body mass, and fat score in white- crowned sparrows, Zonotrichia leucophrys gambelii. Gen Comp Endocrinol 101:242-255.

Woolley CS (1998) Estrogen-mediated structural and functional synaptic plasticity in the female rat hippocampus. Horm Behav 34:140-148.

Woolley CS, McEwen BS (1992) Estradiol mediates fluctuation in hippocampal synapse density during the estrous cycle in the adult rat. J Neurosci 12:2549-2554. 